\title{
A Tale of Two Hispanic Migrants: Lessons in Building Educational Leadership Traits
}

\author{
Ricardo Lumbreras, Jr. \\ Tarleton State University \\ Stephenville, Texas \\ William H. Rupley \\ Texas A\&M University \\ College Station, Texas
}

\begin{abstract}
This inquiry was initiated to delve into the lived experiences of migrant workers and how the themes of poverty, language, cultural differences, mobility, parental support, and mentorship are related to concepts of leadership within educational institutions. Investigators mined for bilingual leadership skills learned by two Latino migrants who made it from the tolling in the agricultural fields of the United States to high levels of educational excellence and leadership in bilingual and multicultural education. These lessons, communicated via personal testimonies, provide much-needed insight for the recruitment of future educational leaders who can use their Latino heritage to build bridges of bilingual educational excellence in the educational systems.
\end{abstract}

Keywords: Latino, migrants, educational leadership, mentors, leadership skills, ELLs.

\section{Introduction/ Review of Literature}

Among educational research, studies concerning migrant worker's lived experiences are abundant. However, there is a significant absence of the research related to these lived experiences and their impact on development of leadership qualities. Our focus was to impact this lack of knowledge by exploring the lived experiences of two successful educators who were once migrant workers and became educational leaders. Dr. Carlos Castillo (a pseudonym) and Mrs. Guadalupe Ortiz (a pseudonym), spent decades in the public-school systems and attained academic and personal excellence that can only be described as extraordinary.

According to the U.S. Census Bureau (2011) Latino students, who compose the fastest growing ethnic group in the country are considered to be in an educational crisis throughout the entire U. S. K-16 educational system (Gandara \& Contreras, 2009; Yosso, 2006). Multiple individuals suggest that compared to 
other Hispanic populations in the United States, Mexicans rank among the lowest regarding educational attainment. They encounter less quality educational opportunities, are more likely to drop out, and are less liable to enrol in U.S. schools (Alba \& Silberman, 2009; Glick \& Hohmann-Marriot, 2007; Suarez -Orozco, Suarez-Orozco, \& Todorova, 2008; Crosnoe \& Lopez-Turley, 2011; Ruiz-de-Velasco \& Fix, 2000; Oropesa \& Landale, 2009). Additionally, for $26 \%$ of U.S. based Mexicans aged 25 and older, a high school diploma is the highest level of education acquired, while only $9 \%$ hold a degree from a fouryear university (Motel and Patten, 2012). Alba \& Silberman (2009) suggest that Mexican students are often enrolled in lower track classes and educational opportunities and advancements are complicated by fears of deportation and living in impoverished conditions. For children of agricultural workers, frequent movement across state lines, schooling disruption, and the responsibilities of work and family lead to high absenteeism (Lopez, 2011; Prewitt, Trotter, \& Rivera, 1990; Gibson \& Bejinez, 2002).

Understanding the educational outcomes of a migrant student compared to a non-migrant youth, or a settled-out migrant, requires consideration of (1) factors that drive child migration and either the subsequent investment or divestment in education; and (2) the barriers to educational success that hinder migrant children in the United States (Miller, 2016). We utilized the lived experiences of those who have struggled and traversed both the migrant lifestyle field and the educational field to mine for better understandings that will help reshape the meaning of school leadership not as a goal or objective, but rather as the outgrowth of involvement for this marginalized group of citizens (VenegasGarcia, 2013).

If we are to learn anything from Latino families, especially migrant families, we must first learn to listen and appreciate what funds of knowledge they bring to education. Researchers Rodriguez-Valls and Torres (2014) propose that migrant families are the epitome of globalization and global communities as a result of their mobility. They are witnesses to realities not experienced by non-migrants, and their prerequisites are global by need and diverse by nature. A necessary, yet often missing perspective in migrant research is the voices of the teachers. Teachers serve as "cultural bridges" between the families and schools. The relationship migrant families have with their teachers, plays a decisive role in determining the extent to which the migrant family will find school a welcoming or alienating place (Valenzuela, 1999).

Multiple studies (Cockcroft, 1995; Darder \& Torres, 2013; Irizarry, 2011; MacDonald, 2004) report that Latinos have played a critical role in the journey of equal educational rights in the United States and were pioneers in the desegregation school movement. However, there remains a widespread belief among many educators and policymakers that Latinos are apathetic about education and that their values are not compatible with the beliefs and values of the school system. Irizarry (2015) supports this contention as he suggests that more often than not, school reform is initiated by politicians and business leaders, the overwhelming majority of whom have never been educators nor taken any courses in education. Ironically, the United States comprises one of 
the largest Spanish-speaking populations in the world, and the language is still described as "foreign" or "alien" thus giving one way of knowing (English) privilege over the other (Spanish).

Monzo and Rueda (2001) reported that the quality of the teacher-student relationship was an important aspect of capitalizing on funds of knowledge in the classroom. Gonzalez, Moll, and Amanti (2005) in their ground-breaking study, Funds of Knowledge, state the underlying purpose of their work finds its' roots in the assumption that the educational process can be greatly enhanced when educators learn about their students' everyday lives. Moreover, Gonzalez et al. (2005) describe experiences in teacher training where the espoused belief was low-income and minority students were more likely to experience failure in school because their home experiences had not provided them the required skills for school success, at the same rate as middle and upper middle-class students. The result being low income and minority students are traditionally offered lessons reduced in complexity to "compensate" for these "perceived" deficits (p. 7).

Migrant educators can serve as role models for their students, as some migrant educators have been migrant students themselves (Menchaca \& Ruiz-Escalante, 1995). They can directly relate to their students' lives, and aid more effectively with the struggles of self-esteem, depression, isolation, rejection and loneliness due to the hardships they face in their lives which also encompass mobility, poverty, and discrimination (Coles, 1971; Green, 2003; Menchaca \& RuizEscalante, 1995; Romanowski, 2003). Villegas and Lucas (2002) whose study on cultural sensitivity and responsiveness training for educators underscores the need for role models, describe the effectiveness with which teachers can respond to diverse students by understanding how they construct knowledge, learning about their lives, being socio-culturally conscious, holding affirmative views on diversity, using appropriate instructional activities and advocating effectively for all students. In doing so, educators and schools would establish what Velez-Ibanez (1983) calls confianza en confianza (trust in confidence); trust in mutual trust, which is an overriding cultural intersection for Mexican-origin populations - a majority of whom make up the migrant population in the U.S. (p. 136).

Our purpose was to explore the following themes of migrant life in the United States, which are supported by the research of Kindler (1995): poverty, language, cultural differences, mobility, parental support, and mentorship. We conducted in-depth interviews with two individuals who were migrant children and ultimately became educational leaders. It is our intent that their experiences become a source from which all educators may learn.

\section{Design and Method}

This inquiry was initiated to delve into the lived experiences of migrant workers and how the themes of poverty, language, cultural differences, mobility, parental support, and mentorship are related to concepts of leadership within educational institutions. The study brought migrant lived experiences to the forefront of inquiry; analyzed the relevance of the abovementioned themes in 
shaping their pedagogical thinking as educational leaders; and gave voice to their experiences and perceptions as agents of change in education. Qualitative research methods were used to extract from the research participants' experiences relevant and critical data for developing an understanding of this type of leadership (Creswell, 2013).

\section{Grounded Theory}

As a methodological approach, grounded theory was utilized because it is primarily an inductive interpretive tool that has the powerful potential for discovery (Charmaz, 2006). Constructivist grounded theory lies squarely within the parameters of the interpretive approach to qualitative studies. This approach was ideally suited for this research (Charmaz, 2006; Creswell, 2013) because of its focus on theory development through learning about the lived experiences of the participants within the embedded hidden networks, situations, and relationships that make visible the hierarchies of power, communication, and opportunity.

These aforesaid considerations explained by the research of Charmaz (2006) and Creswell (2013) further expand that there are greater emphases on the views, values, beliefs, feelings, assumptions, and ideologies of individual participants than on the methodologies of research. Grounded theory has long be recognized as a powerful means to utilize when a theory is not available to aid in explaining or understanding a process (Glasser \& Strauss, 1967). The challenge then falls to the researcher to set aside, as much as possible, theoretical ideas or notions, so the analytical, substantive theory can emerge. Additionally, the researcher must determine when the theory is sufficiently detailed (Corbin and Strauss, 2007).

\section{Critical Race Theory}

Critical race theory (CRT) provides a philosophical framework, a defining lens, and both an epistemological and methodological tool to help analyze the experiences of historically underrepresented populations in the K-20 educational pipeline and the multiple systems of oppression (gender, ethnicity, race, language, class, and socioeconomic status) experienced by those populations (Garcia, 1997; Hurtado, 2003; Ledesma and Calderon, 2015).

As an epistemology, CRT in education generally follows four themes: (1) curriculum and pedagogy; (2) teaching and learning; (3) schooling; and (4) policy/finance and community engagement (Ledesma \& Calderon, 2015). This particular study seeks to affect the first three components via storytelling. Stories provide the necessary context for understanding, feeling, and interpreting the lives of these oppressed voices who are traditionally excluded from dominant pedagogies (Ladson-Billings, 1998; Ledesma \& Calderon, 2015). The salient point being critical qualitative approaches imply an intention to generate knowledge about marginalized groups to advance causes of not just social justice, but to give voice to their struggles and accomplishments while moving that knowledge to spur action (Creswell, 2013; Kincheloe and McLaren, 2000; Lather, 2004). 


\section{Participants}

Participants in the study represent two school districts in differing regions of Michigan. Research participants were chosen for the study because of their unique circumstances as children of migrant workers, migrant workers themselves, and finally educational leaders. Each participant is viewed as a change agent, resulting from their commitment to students and community alike. At the time of this study, each participant was retired from public service, with one still serving as a part-time educational consultant.

Dr. Carlos Castillo (pseudonym) received his Bachelor of Arts from a Michigan university with a major in Spanish and a minor in History. He also was certified to teach at the secondary level. He then received a masters from a university in New Mexico, majoring in Spanish and minoring in Linguistics. His terminal degree was obtained from a Michigan University, with an emphasis in Curriculum and Instruction, Educational Leadership, and Bilingual Education. Dr. Castillo has worked in public education as a teacher, supervisor, director, and assistant superintendent.

Guadalupe Ortiz (pseudonym) began her career in public education as an executive assistant in the Bilingual Education program of a large school district in Michigan. She received a Bachelor of Arts degree in Elementary Education. She also received a Bilingual Endorsement from a Michigan University, which was followed by a Master of Education degree from with a concentration in Educational Leadership and Central Office Certification. She has served as a teacher, resource consultant, supervisor, and administrator at both the elementary and secondary levels.

\section{Data Collection}

Each participant was contacted by telephone and invited to participate in the study. An email was sent out with details of the study and interview questions, with assurances to use pseudonyms for confidentiality, and to confirm voluntary participation in the project. Interviews occurred at the participants' convenience, while allowing for transcription and reflection, and took several weeks to complete. Interviews took place via telephone and each interview was audio-recorded and lasted approximately one hour per participant

Sharing of potentially sensitive information was critical to the success of this research, because richly detailed narratives, based on significant events in their past, were key to cultivating how these experiences shaped their notions of leadership. With that intent in mind, several questions were provided prior to interviews with the express purpose of evoking those stories to frame the understanding. Questions asked were: (1) What did it mean to you to experience poverty? (2) What was the value of learning a second language to you? (3) Have you ever felt excluded because of your cultural differences? (4) What effect did repeat moving have on you? (5) What form of parental support did you experience? (6) Who were the role models that lead you to education? Responses to these questions were reviewed for relevance to each individual question independently by the researchers. Each response was checked for accuracy of transposition for the audio recorded response. Identified variations were 
checked and corrected and a level of $100 \%$ accuracy of transposition was reached for responses to each question in the survey for both participants..

\section{Data Analysis}

Only the authors collected, transcribed, organized, analyzed, and stored the data. Transcribed narratives were the primary unit of analysis for this study, and each personal account was analyzed in relationship to the provided interview questions. Data obtained from the interviews provided a cornucopia of descriptive narratives that allowed the researchers to expose the roots of foundational experiences, principles, and ideologies. The return was an opportunity to harvest deepening thoughts on leadership based on their lived experiences. Line by line transcription was the first step in conceptualizing ideas, then line by line coding of emergent themes and salient details occurred to gather patterns and reap experiences for those entrenched layers of analysis to further complement the study (Creswell, 2013; Charmaz, 2006).

The comparison of narratives demonstrated the shifts in thinking over time each participant endured and captured the intricacy of their experiences. With each transcription, new concepts and patterns were cultivated as their ongoing experiences within the migrant lifestyle banded together to expose the growth of a ripened consciousness and blossoming identities and values. Their accounts of poverty, language, culture, relocation, parental support, and role models became important ingredients as they chose to pursue education and educational leadership roles. Patterns and themes were constructed on the basis of data coming from the perspectives of the participants and the researchers' interpretive analyses (Creswell, 2013; Charmaz, 2006; Strauss \& Corbin, 1994).

\section{Findings}

Dr. Castillo and Mrs. Ortiz shared their richly detailed stories of personal courage and perseverance in the face of continued struggle and in doing so, revealed how their personal backgrounds and family experiences were tied to their actions, their guardianship, and epistemological understandings of leadership.

\section{Lesson One: Poverty}

Poverty affects children's overall development and speech patterns, while simultaneously creating an absence of success models, academic tradition, and differing concepts toward school and schooling (Cardenas, 1974; Miller 2016). Poverty rarely plants the seed or nurtures success in school. Yet, being reared in poverty Dr. Castillo and Mrs. Ortiz cultured academic success. Following, they describe their experiences with poverty.

Dr. Castillo: It takes me back to Asherton, TX, where I was born. Everyone was Mexican, about 2000 people, and 90\% of them were migrants. Poverty was everywhere. But, as long as you had a roof over your head, clothes on your back, frijoles and tortillas, it wasn't a limiting factor. It was just the way of life. As far as the other people in the town, we were all in the same social class; migrant people living and surviving from year to year. Everybody knew each other, everybody's families knew each other. It was an ideal time 
to grow up in. It was familial - both in town and at school. I'm not sugar coating it either - everyone was pretty mellow and calm.

Mrs. Ortiz: I can honestly say, I didn't know I was poor. I had no definition, no experience. I didn't know there was a poor, a middle, and an upper class. We didn't have television or radio. You had people you socialized with, other migrants. We weren't surrounded by crime, like in the ghettos. We just lived and worked. Our parents took us to work.

Analysis of these statements leads to the conclusion that family and community were important components in their childhood and development as educators and educational leaders. As noted by John Dewey (1938), "Every experience is a moving force. Its value can be judged only on the ground of what it moves toward and into" (p.38). In this case, the movement was towards that familial existence and working as part of a team, to support the family and in a larger sense, the community. Helping one another, knowing that your work is for good, and that you're doing something were powerful lessons each would call on later as educational leaders. These characteristics are supported by the beliefs of former Mayor of New York, Rudy Giuliani (2002) who suggests that good people will act when they know their talents are being utilized for good and that they are doing something important.

\section{Lesson Two: Value of a Second Language}

Educators who were migrant students have the added advantage of being able to share some of the same cultural beliefs and values of migrant students (Rueda, Monzo, and Higareda 2004). Former migrant workers bring to their students a wealth of experiential knowledge and capital; one being the value of knowing a second language (Free et al., 2016). Dr. Castillo and Mrs. Ortiz explain the value and role of a second language in their early lives.

Dr. Castillo: In my world (Asherton, TX), which was different from here (Michigan), I felt I was functional in both. But, being immersed into an English speaking environment, like a large high school (more than 2800 students) it brought out self-imposed doubts about my functionality. Whether you were capable of speaking English or not, it took time for that confidence to develop. Once we moved to a smaller high school (less than 700 students), the smaller classes, and smaller environment helped it become less imposing. In Texas I was going at 55 miles per hour linguistically. But, once I was in Michigan, with this new language and new culture, I hit these linguistic speedbumps and I had to slow it down to 45 miles per hour.

For example, the whole notion of wait time today; it wasn't the same then. When a question was posed to the whole class, you're supposed to respond - whoever raises their hand first. I always hesitated because I was still translating the question to Spanish, converting it to English, and nombre (translated: no way!) by the time I came up with the answer, someone else had already blurted it out. I always remember being frustrated because I had the right answer. But, I didn't have the courage and the urgency to raise my hand because I was too shy and thinking I might say the wrong thing. 
Mrs. Ortiz: My parents spoke Spanish, and mom, she spoke nothing but Spanish. My grandpa lived with us then, because he had a stroke and he spoke nothing but Spanish too. In those days, you'd come home for lunch and it was my job to feed him. So, in order to converse with him, I spoke to him in Spanish; I remember that very distinctly. English, of course, was part of the school system, so you learned it - it just happened.

When I was in the second grade, I became the translator for my family. I remember taking my mom and my little brother to register for school because mom didn't speak English. That was the same year I became the bookkeeper. I was considered the smart one I guess; I was just picked; I don't know why. It was a responsibility put to me. And, I don't remember it being a burden to me, because I could do it. I would keep track of how many acres we did, how much per acre, how much we owed to the gas station, and how much we owed to the IGA. I'd sit down with dad and the foreman at the end of the season and compare notes. He (the foreman) was amazed how well I kept records. My reward at the end of the season was a root beer and a pint of ice cream that I'd eat on the way home so I didn't have to share with my brothers!

These statements offer us a unique window into the participants lived experiences. They demonstrate their ability to connect with their past ordeals in an attempt to understand themselves and use that understanding to gather the confidence grown during those difficult times to become more effective leaders. Leadership guru James C. Hunter (1998) describes a leadership model that places leadership at the top. He defines leadership as process that will go the distance and stand the test of time, as long as it is built on authority. Authority may be over a task, a person, or a group of people but must be built upon service and sacrifice. It is at this level of the model that we find what he describes as the Law of the Harvest - we reap what we sow.

Dr. Castillo and Mrs. Ortiz had a bountiful life from which to pull experiences. Their language perspective attest to that they learned to live in both linguistic worlds. While it may have been a necessity at the time, it became an immeasurable advantage later in life. It allowed them to reach back and help those along the same paths they had walked. They were able to tap into the experiences of those who shared their heritage and culture uniquely, powerfully, compassionately, and empathetically. This paradigm allowed them to align their actions and their intentions to become consistent human beings and consistent leaders.

\section{Lesson 3: Exclusion and Cultural Differences}

Children brought up in a culture of migration are less likely to invest in resources such as education that could promote their social mobility (Kandel and Massey, 2002). Mexican students, in particular, are often enrolled in lower track classes (Alba and Silberman, 2009). Educational advancement is often hindered by the anxiety that accompanies the possibility of deportation, living in impoverished conditions, and especially for those transitory children of agricultural farm 
workers, frequent movement across state lines and schooling disruption (Lopez, 2011; Prewitt, Trotter, and Rivera, 1990). Dr. Castillo and Mrs. Ortiz expand on this theory of culture of migration, exclusion, and cultural differences as they detail their first hand witnessing of this phenomenon.

Dr. Castillo: I understood we were in a different part of the world. The people I was used to seeing in town changed colors - that wasn't necessarily a bad thing. It was no longer all mexicanos (Mexicans). In Asherton the only Anglo we had was the sheriff. Once again, my exclusion was mostly selfimposed. I don't recall people pointing out my cultural differences. I still remember the situations where I was really shy. I wasn't shy in Asherton. But, because of the size of the school and different environment I'd always go to the back of the room and sit with the kid in the wheelchair. I didn't have bad self-esteem - I just didn't feel strong enough to stand out. It wasn't really the academics either - it was my Spanish accent. It wasn't very bad, but it was so much different from the English-speaking kids, that I felt different. So, I tried to meld into the woodwork in the back of the class.

Mrs. Ortiz details her experiences with her family and her professional colleagues. When asked, "Have you ever felt excluded because of your cultural differences?" her responses are both alarming and frightening:

Yes, yes I have. I remember during my student teaching sitting in the teacher's lounge eating lunch. The teachers would repeatedly ask me if I came from Mexico. One day I finally answered - "No, did you come from Germany?"

After we moved cities so I could be closer to work (as a bilingual teacher) my family was jealous. My cousins, once I started going to school, they kind of disappeared. They would say they were proud of me, but those extended family friendships ended.

When was I was hired as a bilingual teacher in the district I remember many of the Anglo teachers asking - "Why do you want to infiltrate us? Why are you taking our jobs?" I never understood this. I was paid from the federal dollars allocated for bilingual students. Essentially, the district got a teacher for free, because there were English speaking students in those classrooms too. You just needed to have a bilingual teacher in that room otherwise you'd be out of compliance.

However, once I got enough seniority to bid out of the bilingual position and into a general education position, I did. The day I bid out and let someone else in (a college classmate who had just finished her bilingual teaching endorsement) the Anglo teachers were just furious. I was literally attacked with questions about why I took one of their jobs. Why didn't I just stay in the bilingual room? You see, it was the only way to get another Spanish speaking minority woman into the district - you had to play the game. 
But, it was worth it. I remember when I became an administrator, a fellow administrator, who ironically enough would now be my colleague, asked, "Why do you want to be a principal?" And I answered, "Because I want my children to go to college like yours."

Earlier, it was suggested that the philosophical framework and defining lens through which this research would be examined was CRT. Furthermore, it was also detailed that the focus of this examination would fall under the epistemological and pedagogical themes of education. These statements should awaken in anyone the micro and macro institutional structures of race in education. The marginalized voices of people of color is required for a deep and holistic comprehension of the education system. This belief is supported by the work of Delpit (1988) who argues that one of the tragedies of the field of education is how the dialogue of people of color has been silenced.

CRT researchers, Ledesma and Calderon (2015) further this argument as they suggest that it is simply not enough to use the diverse counter-narratives to disrupt the dominant pedagogies. Instead, these diverse counter-narratives must begin with the lives of the oppressed as these are the voices which are traditionally excluded from dominant pedagogies. For this reason, CR educators must always work to identify and explore the themes of racism, while also being cognizant of what the existing racial hierarchies mean to K-12 education. Very often this is an uncomfortable area for any educator to excavate from within. Reflection of this sort runs the risk of exposing one's own hidden bigotries and shortcomings. Awakening a reactive ethnicity for those who experienced it, or painful and long forgotten memories for those who were complicit in the act. Regardless, accepting that race in education is not a fixed or static phenomenon is critical to embracing the changes needed to bring marginalized voices such as these to the forefront of the discussion.

Dr. Castillo and Mrs. Ortiz's tales are wrought with perseverance. Leadership experts Chris Brady and Orin Woodward (2005) report that budding leaders need patience and perseverance to not only lead, but to learn how to lead. John C. Maxwell (2007), adds additional credibility to these research findings when he suggests that attitude is one of the most contagious qualities a human being can possess. The success, Dr. Castillo and Mrs. Ortiz would later assemble, as a result of their collective experiences as migrants, would lead them to become persistent and conscientious educational leaders.

\section{Lesson 4: Transitory Existence}

Migrant families travel a road of existence many will never know, yet alone understand. According to research (Branz-Spall, Rosenthal, and Wright, 2003; Romanowski, 2003) constant migration has been shown to lead to students being placed in the wrong grade levels as they travel from school to school. Furthermore, they miss significant amounts of classroom time at both the beginning and the end of the year, as well as not being present for state assessments, which are now considered mandatory for grade completion. Finally, students' permanent records are either incorrect or are altogether 
missing. Migrations played an integral part in the development of Dr. Castillo and Mrs. Ortiz educational leadership.

Dr. Castillo: You never have a sense of normalcy - moving is always temporary. One constant was we'd go from Texas to North Dakota. Other times, we went to south Minnesota to work the fields. We lived in a huge migrant camp - about 100 families. It was barrack style living, with gang showers and the only thing separating you from another family was a blanket or a sheet in the doorway. All the noise and commotion of family life with little or no privacy. It added to the transitory existence, where somebody was next door to you and then a week later they were gone. They'd take off because they heard about some crops, or picking, or harvesting somewhere else. People were always coming and going - it was a constant movement of people.

The other constant, starting in third grade, was mom and dad would send my brother and I back to Texas with my uncle to start school on time in August. So, my uncle, his wife, their six kids, and us two - ten people would pack all our belongings in a car to make the three-day trip back to Texas. Plus, my uncle would take a sack of beans and sack of potatoes in the trunk. I think he took them because they were such a good price and they were like a winter stock. With that many mouths to feed, I don't think he took them to resell. Speaking of reselling, he'd always find a used car to tow home too, so he could resell it. He was very entrepreneurial. Three days of driving, sleeping, and living in a car. Honestly, I don't even know how we made it.

We would stay with my mom's sister and her two boys until the end of October when mom and dad would join us. They would stay in Michigan to work the sugar beets. I don't think, or at least I don't remember, talking to them during that time either. There may have been a phone call or two to see how we were doing, but you have to realize that back then, they viewed using a phone as an expensive luxury. I don't remember receiving letters from them either. They (my parents) were very trusting that my aunt was taking care of us. I don't know, but I hope, they sent money to feed us! My aunt was like my second mom and it was really wonderful to have somebody be that good to us. It made that sacrifice bearable.

Mrs. Ortiz: When I was in the fifth grade, dad left mom. He left us in Michigan and moved back to Texas where he married again and had another child with that woman. When we left Michigan, to follow dad, they took us to Texas in a cattle truck - that's how they got people there. There was an old lady who sat on the only sofa in the truck and she never got down. Mom noticed and would say, "This lady never gets down." Well of course the sofa wreaked of urine when we got to Texas and the man just had to throw it away. My uncle found us a house when we got there. It was cold, damp, and full of ants. Ants everywhere. On the floor, on the counters, the walls, in the bathroom. We only had one bed and everyone slept in it. 
Dad went to jail for bigamy. The judge gave him a choice - go to jail or go back to your family. He had to spend a couple months in there, I remember that, because we'd walk there to see him and he'd swear at mom up and down through the bars. Mom took a job at the hospital during that time and would bring us food from there - anything that was wrapped. We had nothing but beans to eat then - mom would boil the beans and we would sell watermelons for a quarter to make money. Most nights we were home alone. One night my older brother and I were home alone and all we had was potatoes. So, we boiled the potatoes and walked to the store to get our free pack of corn tortillas. There were six of us kids - the four youngest were behind us - so we let them eat the potatoes. We were hungry. I know what's it like to be hungry. It's not a good feeling. It was a sad time living in that house with those ants and nothing to eat.

When dad got out, that's when we started migrating, I think that was 1956 or 1957. It was the beginning of our migrant journey that would last until November 1963 - when Kennedy got shot. That year (1963) we worked our butts off. We made $\$ 1000$ dollars and had a brand-new house built in San Antonio, white with turquoise inside - I remember that. When we went back to Texas at the end of the summer the house wasn't done yet. So, we went to pick cotton and that's when we had to live in that farm truck because they didn't have any room for us in the cabins. All we had was blankets on the floor, I don't remember mattresses. The lady would let mom use her kitchen to cook us something to eat and we'd eat in the back of the truck. I don't even know how we took baths - I don't remember. Living in that truck, that summer, was the most horrible and demeaning experience for me. But, in 1963 dad got hit by that tractor and we ended up settling down in Michigan. The moving part was never hard - that was life. Losing that house though, after dad got hit - that was the hardest part - when we lost that house.

Bransford, Brown, and Cocking (2000) posits pedagogy is content knowledge about how individuals learn. This theory underlies effective instruction and is an extremely important part of what teachers need to learn to be effective. Certainly, these contentions can be linked to educational leaders and effective school leadership. If learning about knowledge is a foundational principal of pedagogy, the question becomes, "What can these stories teach us about leadership?" First, we must understand that leadership is much more than just leading people or teaching people about leading; it represents an entire process of acculturation into a new way of learning and thinking. Sarason (2004) says that learning is not a thing; rather, it is a process that occurs in an interpersonal and group context, which is always composed of an interaction of factors such as motivation, cognition, emotion, affect, and attitude. Generally speaking, those interactions occur between people, but when that is not possible, stories of personal experiences must suffice. Lived experiences allow us to find and unearth those counter-narratives so critical to broadening the perspectives institutions have of these often-external groups of people. Certainly, loneliness was a common theme in both participants' tales of migration and the easiest route for them would have been to lose hope and give up. 
But, Woodward and DeMille (2013) believe a few people make a different choice. They take the lonely path of leadership. They are often misunderstood, criticized, and opposed. Their mistakes are part of public gossip, while their successes are often envied and almost always second-guessed. What they start, others come along and manage - but it is important to note, the managers would have nothing to do if the innovators had not set the lead. That Dr. Castillo and Mrs. Ortiz are innovators is both fair and just, based on the occurrences of their young lives and the accomplishments in their professional careers.

\section{Lesson 5: Parental Support}

Qualitative research offers a range of methodological alternatives that allow researchers to fathom the array of cultural and intellectual resources available in-migrant households. This becomes important where households of marginalized groups of people are considered, because they are usually viewed as not only poor economically but in poor in terms of the quality of experiences for the child (Gonzalez, Moll, \& Amanti, 2005). Lack of parental support often falls within this perceived realm of poor experiences.

Auerbach (2011) finds that parents come to schools with their own educational beliefs and priorities, which may not always match those of the school. Furthermore, in the case of immigrant parents, where parent deference to education is stressed, we must help them find their voices to be advocates for the children. Olivia and Aleman (2019) suggest Latina mother leaders continue to strive to provide their children with an education grounded in care, respect, and dignity. For Dr. Castillo and Mrs. Ortiz parental support came in a different form. Following, each reminisces about their parent's educational support.

Dr. Castillo: The level of parental support was excellent. I can remember in early elementary they always talked about going to school - beyond high school - there was no question. I don't ever recall my parents going to the school to talk with the teachers. But they were always in the background. From third grade to eighth grade my brother and I had perfect attendance we never missed a day of school. They always had us ready to go.

Mom and dad could never help with homework and I never missed that because I knew I couldn't go to them - they really didn't have any idea how to help. Mom got to third grade and dad completed eighth grade after the army. It was one of those understood situations where they supported education by sending their two kids down to Texas to start school on time. That to me was the strongest support that I received. They cared so much about schooling and education they were willing to send their kids back home to start school on time.

Mrs. Ortiz: Mom was my biggest supporter. I don't think I would have ever succeeded without seeing what she did and her giving me the verbal support, the motherly support, the warmth and caring. Even after I became a principal, I'd go to her house every week to pick up beans and tortillas for my family. She wanted to help me. That in turn made me a good parent. 
Mom would make sure we had boots, a hat, and a coat for school. She and my aunt would make me flannel slips for my dresses. And, they'd hide some fruit from the boys for me, because they always ate everything before I got home. They would want me to have something to eat when I got home from school too. She would never let us miss school either. If you weren't bleeding and dying, you went to school. She'd give you two aspirins and push you out the door. You had to go to school.

Years later, I remember coming home from college and I'd be crying because I was so tired. I didn't start college until I was 32 and had a family of my own. I felt sorry for myself and I thought nobody cared about me. That's when I realized what mom modeled for me, and I would share with young teachers - "You can cry, but don't quit. Eventually you'll get there. You don't think you'll get there - you don't think you're going to get there - but you will."

Araujo (2006) describes these lessons as Pedagogies of the Field because they depict students' reflections on their motivation, they developed to succeed academically by working in the fields themselves and watching their parents work in the fields. These observations and experiences would build the foundation of the legacy these two educational leaders would leave behind many years later. The concept of a legacy is closely related to what a person's views as a sense of purpose in life (Maxwell, 2007). Regardless of the obstacles these two participants faced, success did not allude them. Their purpose and the support they received was clear; education is important.

As for the source of that strength and the lesson in leadership to be gleaned, Woodward and DeMille (2013) offer a brilliant take: "And, I think a lot of top leaders are mothers who are focused on raising children. They may not be leading a thousand people, but the depth of how they influence their children is worth leading thousands" (p. 71).

\section{Lesson 6: Role Models}

Multiple researchers (Black-Beard, Murrell, and Thomas, 2007; Crisp and Cruz, 2010; Ragins, 1997; Rudolph, Castillo, Garcia, Martinez, and Navarro, 2015) have substantiated that little published research exists on Hispanic experiences with mentors and role models. The existing literature suggests many minorities pay a tax; they work considerably harder while exerting additional time and effort to develop relationships. In all likelihood, the tendency is for them to be mentored by members of the majority class, which highlights those varied power relationships between groups. This should come as no surprise, as Castillo (2013) found Mexican Americans tend to place more importance on all dimensions of mentoring and role modeling than do their non-Mexican American counterparts. Dr. Castillo and Mrs. Ortiz discuss their role models.

Dr. Castillo: My mom and her sisters and brothers, all helped fund my uncle's way into college. He graduated in $1951 \mathrm{I}$ believe. He was the first of two siblings who would go to college. They supported his efforts and they 
promoted him in the family and talked about him highly as the college educated brother. When I was a little kid he used to come from San Antonio to visit the family and he always had a nice shiny car. He had a white shirt and tie and he looked professional - whatever that meant. He looked like the professional teachers we had in school. It really personalized education by identifying somebody in the family that I not only loved, but also someone I really wanted to be like.

The thing is he never took me or anyone else aside that I can recall, to say, "This is what you need to do. Or, this is how you're going to be successful." It was just his modeling of what a good person was and what someone that was a professional looked like. He inspired the whole family - my brother and several cousins - they went on to become nurses, pharmacists, and engineers. He had an exponential effect on a bunch of us. I don't know if anyone ever told him that. Or, if he understood the impact he was having on the younger kids - my generation of the family.

Mrs. Ortiz: Mom was my role model. After college I started looking back at my life and I realized my mom didn't know English. She learned from us. She learned how to read the newspaper. She learned how to crochet by memory - she didn't know how to read those English patterns. When she worked in the pickle factory, she became the line leader and she would translate for the women who were working there seasonally. I was so proud of her.

Mom would tell me that her mom would give her a book and say, "Este libro tiene que decir algo" (This book has to say something). Mom only went to school until the fifth grade - grandma pulled her out of school so she could be a maid for the local judge and help support the family. That's where she learned to cook fried chicken, cornbread, and whatnot because the judge's wife showed her. Now, I'm reading into this because grandma died when she was 44 and left mom to raise her younger brothers and sisters, but I think she wanted her to keep learning. To keep trying to read and learn even though she couldn't go to school. I think it was her way of making it up to her for pulling her out of school. Mom loved to learn. She cried to me once, after I'd graduated from college. She told me she was a smart girl and she could've gone to college too. That was mom though, always full of hope.

In each of us there is a well of talent and ability that was planted long ago. Those talents and abilities must be cared for, nurtured, cultivated, and finally harvested to feed our knowledge. Brady and Woodward (2005) suggest that feeding comes from narratives and that a person sometimes needs a story more than food to stay alive. Dixson and Rousseau (2005) illustrate for us the need of narratives in scholarly research and CRT when they suggest that through narratives, we give voice to those who have been historically dispossessed of power. Ledesma and Calderon (2015) write that narratives which centralize the voice of the minoritized communities pay honor and attest to the richness of the experiences of those too often silenced or cast to the boundaries of pedagogy. 
Personal narratives, stories, and parables have always been powerful tools for illuminating the darkness of ignorance. These chronicles of life, shared by Dr. Castillo and Mrs. Ortiz have shined a light on the experiences of migrant farmworkers who walked in the darkness of morning, to reach the fields of America and begin work at first light. As the sun rises on our epistemological understandings of the correlation between these life experiences and educational leadership, we are reminded to really listen to their stories.

\section{Interpretations of the Findings}

Our findings demonstrate how the seeds of leadership were sown as Dr. Castillo and Mrs. Ortiz worked and learned in the fields as migrants. The circumstances surrounding their upbringing awakened in them the awareness that their lived experiences with poverty, language, cultural differences, mobility, parental support, and mentorship were offset by the narratives they lived and the hope and resilience that resulted. The return was the development of a counter narrative to the partisan dominant narrative that presupposed failure based on their marginalized existence.

Multiple researchers (Eagly and Carli, 2004; Klenke, 1996; Onorato and Musoba, 2015) have written that leadership is a socially constructed paradigm that is shaped by the leaders' context, location, status, values, and lived experiences in society. These experiences and other detailed events led each participant in this study to be distinguished from other marginalized minority groups. For that reason, Dr. Castillo and Mrs. Ortiz's life lessons are paramount to recruiting and developing new educational leaders who share their culture, their heritage, and lived experiences to fix that proverbial leak in the education pipeline as it relates to minority representation and leadership in education.

\section{Significance of this Inquiry}

Our inquiry provided an opportunity to yield knowledge from experienced educational leaders with non-traditional upbringings who also happen to be minorities. Furthermore, their lives allow us to concretely bridge the gap between theory and practice and discussion and action. Validating the experiences of migrant workers, from migrant worker's perspectives, making their lived experiences visible in the context of research and leadership, provides a new field from which to accumulate knowledge about recruiting, developing, and retaining minority educational leaders. We offer a newer or perhaps wider lens to view past paradigms related to leadership through understanding the trials, tribulations, and hardships of marginalized groups of people and their lessons in perseverance, commitment, and hope they bring with them as they grow into new and dynamic educational leaders.

\section{Implications for Educational Leadership}

This research offers actionable steps for educators, instructional leaders, and educational institutions as they continue to seek new and innovative educational leaders for the growing diversified student populations they serve. The actionable steps are as follows: (1) Identify leaders from marginalized groups; (2) Embrace linguistic diversity in leaders; (3) Embrace cultural 
diversity in leaders; (4) Expand the pedagogy of leadership - seek innovation via lived experiences; (5) Embrace Mentorship - particularly for traditionally marginalized individuals; (6) Embrace individuals who can serve as role models despite their educational attainments.

A new line of research that identifies Latino parents as Latinx (Fernandez and Paredes-Scribner, 2018) are challenging the long-held perceptions of people uninvolved or disconnected from their children's education and are actively seeking to engage in the decision-making hierarchy. Within educational institutions, educational leadership needs to take heed of these voices and listen to their stories. Recall, sometimes individuals need a story more than food to survive.

\section{Conclusion}

This research seeks to fill a void in the dialogue about the study of educational leadership by giving voice to the extraordinary experiences of migrant workers and the lessons they learned about leadership. On a theoretical level, this study broadens conversations about leadership from the perspective of marginalized groups of individuals whose lives are a true intersection of a multiple set of oppressions. Moreover, it seeks to minimize over-theorizing and link the premises presented to actual leadership practices. The importance of which is embraced by Ledesma and Calderon (2015) who feel the former occurs all too often in research.

We realize that the conclusions reached are limited to the responses of two individuals and that additional studies should be undertaken to advance the credibility of our conclusion. However, we argue that on a practical level, this study has potential for the addition of these marginalized voices, and perhaps other marginalized groups, in the pedagogical discussions that they would ordinarily not be a part of as a result of the themes this research contends make up the bulk of their existence. Personal and professional choices led Dr. Castillo and Mrs. Ortiz to the educational environment where they were able to champion for the rights of those who shared their culture and heritage both humanely and with a degree of knowledge few before them possessed. Magdaleno (2006) found that leaders who share a cultural heritage with their protégés are often perceived as positive role models who represent their future. Once again, this is critical because as Logue, Hutchens, and Hector (2005) have reported, leadership development programs are positively correlated with cognitive, psychological, and career development.

Multiple published reports (Bordas, 2001; Dreher, (1996); Magdaleno, 2006; Marin and Marine, 1991) contend that the Latino vision of society is one that embraces a collective, people-centered, and familial view of leadership that is highly distinctive from the typical individualistic views that many encounter. For current Latina and Latino educational leaders, mentoring by an experienced educational leader was important; however, being mentored by a leader who shares a common language, similar racial and equity concerns, that can relate to specific cultural experiences they have had, was even more crucial. Generally speaking, Dr. Castillo and Mrs. Ortiz were able to resist the common pitfalls 
people in power typically experience, and move toward a more equitable, interconnected idea of leadership that did not emphasize achieving personal power, but the empowerment of all those who they led.

\section{Future Research}

Since World War I, up to present times, migrant workers have contributed to the abundance that is the American growth and economy, while they and their dependents have suffered malnutrition, health problems, educational deprivation, and poverty. All the while they have been subjected to some of the harshest housing and labor conditions that the United States has ever known. Regrettably, these conditions persist today (Fix and Passel, 1994; Green, 2003). With the limited number of positive educational Latino role models in leadership positions, educational institutions run the risk of being misbegotten in the eyes of the millions of marginalized students who walk their halls each day. Mrs. Ortiz says it this way: "You, the teacher, may be the closest thing to a bible or God a child ever sees. Not that you are omnipotent, but you are their sole source of goodness, and their greatest example of hope." As the migrant journey continues, so to must the research to identify the new leaders who can bring these extraordinary gifts to fruition. As we have argued in similar research (Lumbreras \& Rupley 2017) that schools need to create conditions where all students feel respected and nurtured enough to work hard now, for success in the future

\section{References}

Alba, R., \& Silberman, R. (2009). The children of immigrants and host-society educational systems: Mexicans in the United States and North Africans in France. Teachers College Record, 111(6), 1444-1475.

Araujo, B. (2006) In the process of transformation and overcoming tremendous odds: A case study of migrant farmworkers' enrollment in university. (Doctoral dissertation).

Auerbach, S. (2011). Learning from Latino families. Schools, Families, Communities, 68(8), 16-21.

Black-Beard, S., Murrell, A., \& Thomas, D. (2007). Unfinished business: The impact of race on understanding mentoring relationships. In B. Rose-Ragins \& K. Kram (Eds.), The handbook of mentoring at work: Theory, research, and practice (pp. 223-248). Thousand Oaks, CA: SAGE

Bordas, J. (2001). Latino leadership: Building a Humanistic and diverse society. Journal of Leadership Studies. doi: 10.1177/107179190100800208

Brady, C., \& Woodward, O. (2005). Launching a leadership revolution. Mastering the five levels of influence. New York, NY: Business Plus.

Bransford, J.D., Brown, A.L., \& Cocking, R.R. (2000). How people learn: Brain, mind, experience, and school. Washington, D.C.: National Academy Press.

Branz-Spall, M.R., Rosenthal, R., \& Wright, A. (2003). Children of the road: Migrant students, our nation's most mobile population. The Journal of Negro Education, 71(1), 55-62. doi: $10.2307 / 3211290$

Cardenas, J. (1974). An education plan for the Denver public schools. U.S. Department of Health, Education and Welfare. Retrived from http://files.eric.ed.gov/fulltext/ED096046.pdf

Castillo, C.P. (2013). Hispanic graduates students' conceptualizations of the ideal mentor (Unpublished masters' thesis). Texas A\&M International University, Laredo.

Charmaz, K. (2006). Constructing grounded theory: A practical guide through qualitative analysis. Thousand Oaks, CA: SAGE. 
Cockfort, J.D. (1995). Latino/as in the struggle for equal education. New York: Franklin Watts.

Coles, R. (1971). Children of crisis: Vol. 2. Migrant, sharecroppers, mountaineers. Boston: Little and Brown.

Corbin, J., \& Strauss, A. (2007). Basics of qualitative research: Techniques and procedures for developing grounded theory (3 ${ }^{\text {rd }}$ ed.). Thousand Oaks, CA: Sage.

Creswell, J.W. (2013). Qualitative inquiry \& research design. Choosing among five approaches. Thousand Oaks, CA: SAGE.

Crisp, G., \& Cruz, I. (2010). Confirmatory factor analysis of a measure of "mentoring" among undergraduate students attending a Hispanic serving institution. Journal of Hispanic Higher Education, 9, 232-244. doi: 10.1177/1538192710371982

Crosnoe, R., \& Lopez-Turley, R. (2011). The K-12 educational outcomes of immigrant youth. Future of Children, 21(1), 129-152. NIHMSID: NIHMS889529

Darder, A., \& Torres, R.D. (2013). Latinos and education: A critical reader. New York: Routledge.

Delpit, L. (1998). The silenced dialogue: Power and pedagogy in educating other people's children. Harvard Educational Review, 58, 280-298. doi: 10.17763/haer.58.3.c43481778r528qw4

Dewey, J. (1938). Experience and education. New York, NY: TOUCHSTONE

Dixson, A.D., \& Rousseau, C.K. (2005). And we still not saved: Critical race theory in education ten years later. Race Ethnicity and Education, 8, 7-27. doi:10.1080/1361332052000340971

Dreher, G.F. \& Cox, T.H. (1996). Race, gender, and opportunity: A study of compensation attainment and the establishment of mentoring relationships. Journal of Applied Psychology.

Eagly, A.H., \& Carli, L.L. (2004). Women and men as leaders. In J. Antonakis, R.J. Steinberg, \& A.T. Cianciolo (Eds.), The nature of leadership, (pp. 279-301). Thousand Oaks, CA: Sage.

Fernandez, E., \& Paredes-Scribner, S.M. (2018). "Venimos para que se oiga la voz": Activiating community cultural wealth as parental educational leadership. Journal of Research on Leadership Education, 13(1), 59-78. doi: 10.1177/1942775117744011

Fix, M., \& Passel, J. (1994). Immigration and immigrants: Setting the record straight. Washington, DC: Urban Institute Press.

Free, J.L., \& Kriz, K (2016). “They know there is hope:" How migrant educators support migrant and their families in navigating the public-school system. Children and Youth Services Review, 69, 184-192. doi: 10.1016/j.childyouth.2016.08.003

Garcia, A.M. (1997). Chicana feminist thought: The basic historical writings. New York: Routledge.

Gibson, M.A., \& Bejinez, L.F. (2002). Dropout prevention: How migrant education supports Mexican youth. Journal of Latinos and Education, 1(3), 155-175. doi: 10.1207/S1532771XJLE0103_2

Giuliani, R.W. (2002). Leadership. New York, NY: Hyperion.

Glick, J.E., \& Hohmann-Marriott, B. (2007). Academic performance of young children in immigrant families: The significance of race, ethnicity, and national origins. The International Migrant Review, 41(2), 371-402. doi: 10.1111/j.1747-7379.2007.00072.x

Gonzalez, N., Moll, L.C., Amanti, C. (2005). Funds of knowledge: Theorizing practices in households, communities, and classrooms. Mahwah, NJ: Lawrence Erlbaum Associates, Publishers.

Green, P.E. (2003). The undocumented. Educating the children of migrant workers in America. Bilingual Research Journal, 27(1), 51-71. doi: 10.1080/15235882.2003.10162591

Hunter, J.C. (1998). The servant: A simple story about the true essence of leadership. New York, NY: Crown Business. 
Hurtado, A. (2003). Voicing Chicana feminisms: Young women speak out on sexuality and identity. New York, NY: New York University Press.

Irizarry, J.G. (2011). The Latinization of U.S. schools: Successful teaching and learning in shifting cultural contexts. Boulder, CO: Paradigm Publishing.

Irizarry, J.G. (2015). What Latino students want from school. Educational Leadership, 72(6), 66-71.

Kandel, W., \& Massey, D.S. (2002). The culture of Mexican migration: A theoretical and empirical analysis. Social Forces, 80(3), 981-1004. Doi: 10.1353/sof.2002.0009

Kincheloe, J.L. \& McLaren, P. (2000). Rethinking critical theory and qualitative research. In N.K. Denzin \& Y.S. Lincoln (Eds.), Handbook of qualitative research (2 $2^{\text {nd }}$ ed). Thousand Oaks, CA: Sage.

Kindler, A.L. (1995). Education of migrant children in the United States. Directions in Language and Education: National Clearinghouse of Bilingual Education, 1(8), 8 pages.

Klenke, K. (1996). Women and leadership: A contextual perspective. New York, NY: Springer.

Ladson-Billings, G. (1998). Just what is critical race theory and what's it doing in a nice field like education? International Journal of Qualitative Studies in Education, 11(1), 724. doi: $10.1080 / 095183998236863$

Lather, P. (2004). Critical inquiry in qualitative research: Feminist and poststructural perspectives: Science "after truth." In K. deMarrais \& S.D. Lapan (Eds.) Foundations for research: Methods of inquiry in education and the social sciences. Mahwah, NJ: Erlbaum.

Ledesma, M.C., \& Calderon, D. (2015). Critical race theory in education: A review of past literature and a look to the future. Qualitative Inquiry, 2(3), 206-222. doi: $10.1177 / 1077800414557825$

Logue, C.T., Hutchens, T.A., \& Hector, M.A. (2005). Student leadership: A phenomenological exploration of postsecondary experiences. Journal of College Student Development, 46, 393-408. doi: 10.1353/csd.2005.0039

Lopez, M.P. (2011). Reflections on educating Latino and Latina undocumented children: Beyond Plyer v. Doe. Seton Hall Law Review, 35(4). 1373-1406.

Lumbreras, R., \& Rupley, W. H. (2018). Educational experiences of ELL Educators: Searching for Instructional Insights to Promote ELL Students Learning. Educational Research for Policy and Practice, 18(1), 17-38. DOI: 10.1007/s10671-017-9225-Z

MacDonald, V.M. (2004). Latino education in the United States: A narrative history from 1513-2000. New York: Palgrave.

Magdaleno, K.R. (2006). Mentoring Latino school leaders. Leadership, 36(1), 12-14.

Martin, G. \& Marine, B.V. (1991). Research with Hispanic populations. Newbury Park: Sage Publications.

Martin, G. \& Marine, B.V. (1991). Research with Hispanic populations. Newbury Park: Sage Publications.

Maxwell, J.C. (2007). The 21 irrefutable laws of leadership: Follow them and people will follow You. Nashville, TN: Thomas Nelson.

Miller, K. (2016). Education across borders: The relationship between age at migration and educational attainment for Mexico-U.S. child migrants. Teachers College Record, 118, (010307), 1-48.

Menchaca, V.D., \& Ruiz-Escalante, J.A. (1995). Instructional strategies for migrant students. ERIC Digest. Retrieved from: http:// files.eric.ed.gov/fulltext/ED388491.pdf

Monzo, L., \& Rueda, R. (2001). Professional roles, caring, and scaffolds: Latino teachers' and paraeducators' interactions with Latino students. American Journal of Education, 109(4), 438-471. doi: 10.1086/444335

Motel, S., \& Patten, E. (2012). The 10 largest Hispanic origin groups: Characteristics, rankings, top counties. Washington, DC: Pew Hispanic Center.

Oliva, N., \& Aleman, E. (2019). A Muxerista politics of education. Latina mother leaders enacting educational leadership and policy advocacy. Educational Policy, 33(1), 6787. doi: $10.1177 / 0895904818807323$ 
Onorato, S., \& Musoba, G.D. (2015). La lider: Developing a leadership identity as a Hispanic woman at a Hispanic-serving institution. Journal of College Student Development, 56(1), 15-31. doi: 10.1353/csd.2015.0003

Oropesa, R.S., \& Landale, N.S. (2009). Why do immigrant youth who never enroll in U.S. schools matter? School enrolment among Mexicans and Non-Hispanic Whites. Sociology of Education, 82(3), 240-266. doi: 10.1177/003804070908200303

Prewitt, J., Trotter, R., \& Rivera, V. (1990). The effects of migration on children: An ethnographic study. State College, PA. Centro de Estudios Sobre la Migracion.

Ragins, B.R. (1997). Antecedents of diversified mentoring relationships. Journal of Vocational Behavior, 51(1), 90-109. doi: 10.1006/jvbe.1997.1590

Rodriguez-Valls, F., \& Torres, C. (2014). Partnerships \& networks in migrant education. Empowering migrant families to support their children's success. Multicultural Education, 21(3-4), 34-38.

Romanowski, M.H. (2003). Meeting the unique needs of the children of migrant farm workers. The Clearing House, 77(1), 27-33. doi: 10.1080/00098650309601225

Rudolph, B.A., Castillo, C.P., Garcia, V.G., Martinez, A., \& Navarro, F. (2015). Hispanic graduate students' mentoring themes: Gender roles in a bicultural context. Journal of Hispanic Higher Education, 14(3), 191-206. doi: $10.1177 / 1538192714551368$

Rueda, R., Monzo, L., \& Higareda, I. (2004). Appropriating the sociocultural resources of Latino paraeducators for effective instruction with Latino students: Promise and problems. Urban Education, 39(1), 52-90. doi: $10.1177 / 0042085903259213$

Ruiz-de-Velasco, J., \& Fix, M. (2000). Overlooked and underserved: Immigrant students in U.S. secondary schools. Washington, D.C.: The Urban Institute.

Sarason, S.B. (2004). And what do you mean by learning? Portsmouth, NH: Heinemann.

Strauss, A. \& Corbin, J. (1994). Grounded theory methodology. In N.K. Denzin \& Y.S. Lincoln (Eds.), Handbook of qualitative research ( $\left.2^{\text {nd }} \mathrm{ed}.\right)$. Thousand Oaks, CA: Sage.

Suarez-Orozco, C., Suarez-Orozco, M., \& Todorova, I. (2008). Learning a new land:Immigrant students in American society. Cambridge, MA: Harvard University Press.

Valenzuela, A. (1999). Subtractive schooling: U.S.-Mexican youth and the politics of caring. Albany, NY: State University of New York Press.

Velez-Ibáñez, C. G. V. (1983). Bonds of mutual trust: The culture systems of rotating credit associations among urban Mexicans and Chicanos. Rutgers University Press.

Venegas-Garcia, M. (2013). Leadership for social change: Learning from the perspectives of Latina/Chicana activist educators. Journal of School Leadership, 23, 685-709. doi: $10.1177 / 105268461302300406$

Villegas, A., \& Lucas, T. (2002). Educating culturally responsive teachers: A coherent approach. Albany, NY: SUNY Press.

Woodward, O., \& DeMille, O. (2013). LeaderShift: A call for Americans to finally

Yosso, T.J. (2006). Critical race counterstories along the Chicana/o educational pipeline. New York, NY: Routledge. 